\title{
Winds of Change
}

\author{
Patrick Fitch
}

Change is the law of life. And those who look only to the past or the present are certain to miss the future. - John F Kennedy

T've been here before. As some of you will remember, I was the Director of Finance of the Canadian Society of Hospital Pharmacists (CSHP) from 2008 to 2012. Now I'm back, to begin a 3-year term as presidential officer on October 22 in Regina.

In some ways, this is a return to familiar ground. Regina is where I grew up and where I worked my first job in pharmacy. The prospect of returning to my hometown to begin this executive term inspired me to reflect on some of the changes that have occurred since I left CSHP Council a few years ago.

Council is now the Board, and the Director of Finance is now the Treasurer. The Summer Educational Sessions have been sunsetted, and 2016 marks the first year of a new format for the Society's Annual General Meeting (AGM). That meeting was held in conjunction with the Saskatchewan Branch's own AGM and Educational Sessions 2016 on Saturday, October 22.

The Professional Practice Conference will also have a new look, as the conference moves to the InterContinental Toronto Centre in 2017. One thing that will not change is the high quality of the program that is being planned by the Educational Services Committee.

The programs leading to the PharmD as first professional degree are now the norm across the country, with programs in place or approved for the near future in almost all pharmacy faculties. These PharmD programs, with an increased emphasis on experiential education, are well placed to educate student pharmacists for an exciting new era of expanded scopes of practice. Across Canada, pharmacists are prescribing independently, ordering laboratory tests, and administering vaccines and other injections, among various other new activities.

The Supreme Court of Canada's decision in Carter v. Canada and the passage of Bill C-14 have created the prospect that pharmacists may be asked to participate in cases of medical assistance in dying or may be asked to advise other health care providers caring for patients who have asked for such assistance.
This is uncharted territory for our profession, and to date it is unknown what pitfalls or opportunities will present themselves in this new practice area. To help guide pharmacists, CSHP recently published "Physician-Assisted Dying: Position Statement" (www. cshp.cal dms/dmsView/1_PhysicianAssisted-Dying-Position-

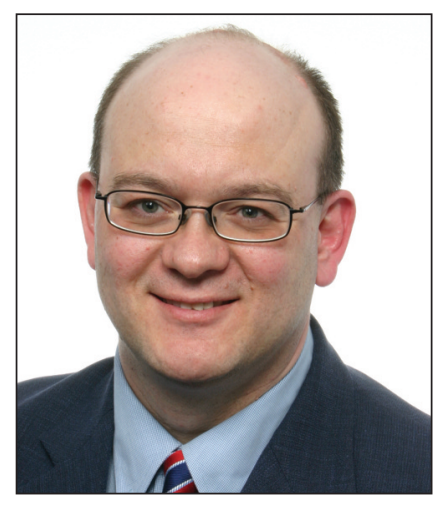
Statement-\%28English\%29.pdf). In this position statement, CSHP advocates for respect for the rights and autonomy of the patient; for protection under federal law for all pharmacists who choose to participate in activities related to medical assistance in dying; and for each health care professional's right to conscientious objection, provided that continuity of care is not compromised.

Finally, social media has taken over the world. When I first joined CSHP Council, "blog" was a new term. Now, it seems like everyone has a blog, an Instagram account, a Twitter feed, a LinkedIn profile, or some other platform to voice their opinions. While there's a lot of chaff out there, these technologies also present tremendous opportunities to connect with our peers, experts, and our patients. I admit to having 3 Twitter accounts, one of which is for professional use. I follow journals, professional societies, and other pharmacists. Twitter has become my main way to keep informed in the profession, and I'm hoping to use Twitter to connect with CSHP members during my years on the Executive. So follow me at @ICU_Patrick, and let's see what the next 3 years have in store.

Patrick Fitch, BSP, ACPR, became President Elect and Internal Liaison for the Canadian Society of Hospital Pharmacists at the Board meeting following his election during the Annual General Meeting in October 2016. 